\title{
Avoiding or mitigating flooding: Bottom-up drivers of urban resilience to climate change in the USA
}

\author{
Koen de Koning ${ }^{\mathrm{a}, *}$, Tatiana Filatova ${ }^{\mathrm{a}, \mathrm{d}}$, Ariana Need ${ }^{\mathrm{b}}$, Okmyung Bin $^{\mathrm{c}}$ \\ ${ }^{a}$ Department of Governance and Technology for Sustainability (CSTM), University of Twente, P.O. Box 217, 7500AE Enschede, the Netherlands \\ ${ }^{\mathrm{b}}$ Department of Public Administration (PA), University of Twente, P.O. Box 217, 7500AE Enschede, the Netherlands \\ ${ }^{\mathrm{c}}$ Department of Economics, Center for Natural Hazards Research, East Carolina University, Greenville, NC 27858, United States \\ ${ }^{\mathrm{d}}$ School of Information, Systems and Modeling, Faculty of Engineering and IT, University of Technology Sydney, 15 Broadway, Ultimo NSW 2007 , Australia
}

A R T I C L E IN F O

\section{Keywords:}

flood adaptation

coastal flooding

retreat

surveys

housing market

Bayesian statistics

\begin{abstract}
A B S T R A C T
Coastal areas around the world are urbanizing rapidly, despite the threat of sea level rise and intensifying floods. Such development places an increasing number of people and capital at risk, which calls for public flood management as well as household level adaptation measures that reduce social vulnerability to flooding and climate change. This study explores several private adaptation responses to flood risk, that are driven by various behavioral triggers. We conduct a survey among households in hazard-prone areas in eight coastal states in the USA, of which, some have recently experienced major flooding. While numerous empirical studies have investigated household-level flood damage mitigation, little attention has been given to examining the decision to retreat from flood zones. We examine what behavioral motives drive the choices for flood damage mitigation and relocation separately among property buyers and sellers. Hence, we focus on the drivers that shape demand for future development in flood-prone cities. We find that households' choices to retreat from or to avoid flood zones (1) are highly sensitive to information that provokes people's feelings of fear, and (2) rely on hazardous events to trigger a protective action, which ideally would take place well before these events occur. We highlight that major flooding may cause a potential risk of large-scale outmigration and demographic changes in floodprone areas, putting more low-income households at risk. Therefore, coordinated policies that integrate bottomup drivers of individual climate adaptation are needed to increase urban resilience to floods.
\end{abstract}

\section{Introduction}

Flooding is the most frequent and consequently also one of the costliest natural disasters. In the U.S. alone it causes \$7.96 Billion in damages per year on average (National Weather Service, 2018). With the changing climate, its impacts are expected to grow due to more frequent extreme rainfall events and sea level rise (Jongman et al., 2012; UNISDR, 2011; Winsemius et al., 2016). Therefore, climate adaptation policies should focus on effective strategies to reduce adverse impacts of increasing flood risk (Dronkers et al., 1990). To be effective in increasing resilience to floods, climate adaptation policies should span across scales (Adger et al., 2005) making it important to understand the endogenous bottom-up drivers of societal vulnerability to flood hazards. How is flood risk perceived by individual households? What motivates homeowners' protective responses to flood risk? Are people prepared to move away from hazard-prone areas when the risk becomes too high? Does it differ among people who are already in the flood-zone compared to those who are still choosing a place to live? Answering these questions requires an understanding of people's perception of the hazard, and the cognitive processes that drive their motivation to adopt protective measures and adapt to increasing risk.

Behavioral science offers a rich set of theories that elaborate on the cognitive processes behind individual decision making. Potentially, each of them may lead to different hypotheses about how people choose to protect themselves against flood risk. The probability of flooding and anticipated damages, the two main variables of expected utility theory, are the most common factors in explaining what motivates risk management behavior (Bubeck et al., 2012). Expected utility theory postulates that people weigh the costs of living in a hazard zone (and of adopting risk mitigation measures) by the probability of a flood occurring, and the damages associated with a flood of a certain reoccurrence interval. In practice, the probability of a flood and its expected impacts could be perceived subjectively, vary between different people, and can change over time in response to experience with floods and

\footnotetext{
* Corresponding author.

E-mail addresses: k.dekoning@utwente.nl (K. de Koning), t.filatova@utwente.nl (T. Filatova), a.need@utwente.nl (A. Need), BINO@ecu.edu (O. Bin).
} 
exchange of information. A more extensive theory which links risk appraisal with coping appraisal is protection motivation theory (Grothmann and Reusswig, 2006; Kahneman and Tversky, 1979), adding behavioral variables such as perceived control efficacy, perceived self-efficacy and perceived control costs. This theory suggests that in order to consider risk management strategies people should perceive a minimum level of risk. If they do, they proceed with weighing the costs and effectiveness of the risk management strategies, as well as their perceived control over the risk. Protection motivation theory also encompasses non-protective responses, such as fatalism or denial, that negatively motivates protective responses. Another psychological theory on risk mitigation behavior is the psychometric paradigm or the affect heuristic, which focuses on decision making driven by feelings of dread and fear (Slovic et al., 2005). The latter is also included in protection motivation theory. Some of these theories focus on perceptions alone, like the affect heuristic (Slovic et al., 2004) and the psychometric paradigm, while others (such as protection motivation theory) include behavioral responses as well. We explore a multitude of variables that are relevant in households' motivation to adopt various risk management measures, including the choice to move away or avoid the hazard zones. We empirically assess the effects of the variables of multiple theories to examine what drives households' decisions at multiple stages, and how this affects their vulnerability to flooding. We use the variables of protection motivation theory as the basis, because it is the most elaborate framework and the most widely used in explaining homeowners' risk mitigation behavior (Bubeck et al., 2012; Grothmann and Reusswig, 2006). Moreover, it includes most of the variables that are present in other theories as well.

There are numerous empirical studies grounded in various theoretical frameworks that attempt to explain risk mitigation behavior in response to flooding (as reviewed by: Kellens et al., 2013; Bubeck et al., 2012; Koert et al., 2017). Affect heuristics and the psychometric paradigm are frequently studied (Ge et al., 2011; Ho et al., 2008; Keller et al., 2006; Terpstra, 2011) as well as concepts from protection motivation theory (Grothmann and Reusswig, 2006; Poussin et al., 2014; Zaalberg et al., 2009). Most of these behavioral theories have been used to explore individual choices when facing flood risks (Bubeck et al., 2012; Kellens et al., 2013; van Valkengoed and Steg, 2019) assuming households take only incremental actions such as taking flood insurance. In light of climate change, however, transformative adaptation actions - such as relocation from a flood zone - are expected to become more prominent (Kates et al., 2012). In the long term, planned retreat as opposed to flood protection (e.g. levees, dikes, seawalls) or damage mitigation (e.g. flood proofing, drainage systems) - is a viable policy option to overcome the increasing costs of flood protection and increasing flood damages (Song et al., 2018; Filatova, 2014). The implications of a high-impact policy such as planned retreat has been studied, for example, by Freudenberg et al. (2016), and on what drives public support (see: Alexander et al., 2012; Rey-Valette et al., 2019). Yet, it requires major planning and is not necessarily supported by the households at risk. Given that planned retreat is a major political intervention, it would take many years to implement. Especially a larger scale it would be difficult to gain public/political support, and many obstacles would have to be crossed. Meanwhile retreat as a private decision of households may become increasingly prominent, in particular following a major flood event such as was observed after hurricane Katrina (Zaninetti and Colten; 2012), which puts high-income households in a more favorable position over low-income households, who may find themselves trapped due to the lack of resources to move (Black et al., 2013). While avoiding flood zones is an effective way of reducing the risks, the choice to live there can be fueled by a desire to live close to water or have an ocean view. Having rich environmental amenities may result in up to a $36 \%$ premium for properties that are located in a flood zone (Beltrán et al., 2018). The expansion of urban development into hazard-prone areas is the largest driver of risks in a climate changing world, not the growing probabilities of hazards (IPCC, 2012; Wong et al., 2014). Hence, it is important to understand what cognitive mechanisms drive the balance between the costs of living in a hazard zone and enjoying the benefits of coastal locations including environmental amenities. Will an increase in hazard events shift this balance and prompt a household to move out of a flood-zone?

Little is known about what drives individual households to reconsider their location choice and to relocate to higher ground. To the best of our knowledge the only exception is the work of Treuer et al. (2018). They recorded peoples' willingness to relocate in a virtual simulation experiment where people are asked to imagine living in a house in south Florida, while the experiment takes people forward in time with increasing risk and sea level rise. However, this lab experiment does not provide empirical evidence for people's preparedness to move when it concerns their own home. To address this gap, we conducted a survey among 1040 households in coastal hazard-prone areas in the U.S., some of which have recently experienced major flooding. We study what behavioral factors drive the relationship between flood mitigation and outmigration among property buyers and sellers. These households shape the demand for locations - and consequently future urbanization patterns - in flood-prone cities. Therefore, the survey covers the choice of location where to live, how people protect themselves against river and coastal flooding, and how this impacts their vulnerability to flooding and possible future impacts due to climate change. It aims to assess (1) how households respond to flood risk in terms of choosing where to live and how to protect themselves against flooding, (2) which factors change households' perceptions towards flood risk and how their perceptions affect their adaptation choices, and (3) how households' responses to flood risk potentially impacts their vulnerability to flooding in a changing climate. Studies on homeowners' flood risk management, including many surveys, focus primarily on protective measures such as flood insurance and flood proofing (Bubeck et al., 2012, 2013; Grothmann and Reusswig, 2006; Terpstra, 2011; Zaalberg et al., 2009). They employ cognitive decisionmaking models such as protection motivation theory as well as theories of affective decision making to explain why some people protect themselves and others do not. This article adds to the literature by including location choice as a protective response to flood risk. Those who live in areas that are prone to flooding can choose to adopt protective measures. Yet, a natural line of defense against flooding is choosing not to live in these areas in the first place- Indeed, households can minimize the damage by adopting measures that reduce an impact to structures and property in case of flooding, or they can minimize their exposure by moving out of the flood zones or avoiding buying a home in these areas. The latter will become increasingly important in the context of climate change when sea levels rise, and flood hazards increase. As flooding events become more frequent and severe and exposure increases due to urbanization (Jongman et al., 2012; UNISDR, 2011; Wong et al., 2014), local flood climate adaptation measures become more costly and less effective. It brings attention to alternative flood adaptation strategies such as avoiding areas with increasing hazard either through planned retreat or bottom-up relocation. Our survey assesses how information, learning and experience with flooding alter households' responses to flood risk and the individual factors (affective and cognitive) that drive the latter. Our study draws upon unique data, as the survey sample includes respondents who were personally affected by Hurricane Harvey in 2017. By focusing on how buyers and sellers respond to flooding events, we address the choices of potential newcomers to flood risk areas (buyers) as well as of people who are already there (sellers), but could take a decision to move away from the hazard. 


\section{Data and methods}

\subsection{Study area and data}

This survey study ${ }^{1}$ focuses on two types of flooding that are both caused by hurricanes - river and coastal flooding. Our study area consists of eight states in the U.S. along the Gulf and Atlantic coast that are known to have periodic flooding from hurricanes: Texas, Louisiana, Mississippi, Alabama, Florida, Georgia, South Carolina and North Carolina. Our sample was focused on areas close to the coast and waterways, focusing on those areas where flood risk is most relevant. We conducted the survey as an online questionnaire ${ }^{2}$ in January and February 2018 among buyers and sellers separately who were either active on the market at the time of the survey or had recently bought or sold a property in the study area. We were unable to control the number of responses per state, as we found it to be challenging enough to get enough responses per state. The buyer and seller survey were sent out to different people, and thus no respondent could fill in the survey in both roles as seller and buyer. The identification of active buyers and sellers was done through a series of qualifying questions: 'are you currently selling your house?', 'are you currently in the market to purchase an owneroccupied house?' and 'have you identified a property on which you are considering making or have made an offer?' (Appendices B and C, part C.1). We aimed to sample as many active buyers and sellers as possible. Furthermore, we included households that had bought or sold their residential property in the past 12 months to increase our sample size. This group responded affirmatively to the questions 'did you purchase the home you live in within the past 12 months?' or 'have you sold your house within the last twelve months?'. Of the responding buyers only $12.5 \%$ were active in the market, while $42.0 \%$ of the responding sellers were active on the market at the time of the survey. It proved to be challenging to sample buyers who were active on the market, particularly because the survey included specific questions about a property they were likely going to buy. This required buyers that already had a specific property in mind for which they were considering making or had made an offer. Buyers that had no interest in any specific property were excluded from the survey.

Table 1 shows the number of buyer and seller responses, where they come from and their household income. The majority of respondents are from Florida and Texas which have been hit by Hurricane Matthew in October 2016 and Hurricane Harvey in August 2017, respectively. Hurricane Harvey caused severe rainfall and is ranked as the second costliest hurricane on the U.S. mainland after Hurricane Katrina, causing $\$ 126$ billion worth of damages (National Hurricane Centre, 2018). A total of 72 respondents in our survey (6.7\%) had experienced damage from a flood.

\subsection{Variables of interest and ways to measure them}

Our primary interest is in revealing behavioral factors that drive a major choice of homeowners among various flood risk management strategies: to protect property from flood damage when choosing floodprone locations or to avoid properties in hazard locations entirely. Various behavioral factors, including people's experience with flooding, were formulated into specific variables (Table 2). Subsequently we selected the questions from the survey that measure these variables (shown in the second column of Table 2). The questions in the survey have been carefully formulated in line with existing surveys (e.g. van

\footnotetext{
${ }^{1}$ The questionnaire has been reviewed and approved by the University of Twente Institutional Ethical Committee and also certified by East Carolina University Institutional Review Board. All the respondents gave their consent before answering the survey.

${ }^{2}$ The sampling was assisted by a U.S. survey company 'Survey Design \& Analysis' through their georeferenced databases.
}

Table 1

Demographics of survey respondents.

\begin{tabular}{|c|c|c|c|}
\hline & Buyers & Sellers & Combined \\
\hline Number of responses & 519 & 521 & 1040 \\
\hline Active on the market & $12.5 \%$ & $42.0 \%$ & $27.3 \%$ \\
\hline \multicolumn{4}{|l|}{ State } \\
\hline Alabama & $6.6 \%$ & $6.5 \%$ & $6.5 \%$ \\
\hline Florida & $30.6 \%$ & $27.8 \%$ & $29.2 \%$ \\
\hline Georgia & $9.6 \%$ & $11.3 \%$ & $10.5 \%$ \\
\hline Louisiana & $5.4 \%$ & $4.0 \%$ & $4.7 \%$ \\
\hline Mississippi & $1.7 \%$ & $3.8 \%$ & $2.8 \%$ \\
\hline North Carolina & $12.9 \%$ & $15.0 \%$ & $13.9 \%$ \\
\hline South Carolina & $8.9 \%$ & $7.5 \%$ & $8.2 \%$ \\
\hline Texas & $24.3 \%$ & $24.0 \%$ & $24.1 \%$ \\
\hline \multicolumn{4}{|l|}{ Flood zone } \\
\hline Outside & $60.1 \%$ & $67.4 \%$ & $63.8 \%$ \\
\hline 100-year recurring flood & $6.0 \%$ & $9.0 \%$ & $7.5 \%$ \\
\hline 500-year recurring flood & $6.0 \%$ & $5.8 \%$ & $5.9 \%$ \\
\hline Unknown & $27.9 \%$ & $17.9 \%$ & $22.9 \%$ \\
\hline Experience with flooding & $24.7 \%$ & $25.7 \%$ & $25.2 \%$ \\
\hline \multicolumn{4}{|l|}{ Household income } \\
\hline Less than $\$ 30,000$ & $11.0 \%$ & $9.6 \%$ & $10.3 \%$ \\
\hline$\$ 30,000-\$ 49,999$ & $16.4 \%$ & $12.7 \%$ & $14.5 \%$ \\
\hline$\$ 50,000-\$ 74,999$ & $22.5 \%$ & $24.7 \%$ & $23.7 \%$ \\
\hline$\$ 75,000-\$ 99,999$ & $19.5 \%$ & $23.6 \%$ & $21.5 \%$ \\
\hline$\$ 100,000-\$ 149,999$ & $19.8 \%$ & $17.3 \%$ & $18.6 \%$ \\
\hline$\$ 150,000-\$ 199,999$ & $4.2 \%$ & $5.4 \%$ & $4.8 \%$ \\
\hline$\$ 200,000$ or more & $3.7 \%$ & $2.5 \%$ & $3.1 \%$ \\
\hline Prefer not to answer & $2.9 \%$ & $4.2 \%$ & $3.6 \%$ \\
\hline
\end{tabular}

Duinen et al., 2015; Lindell and Hwang, 2008; Bubeck et al., 2013). The buyer and seller survey consisted of 37 and 44 questions respectively. We ended up with 12 and 13 questions for the buyer and seller survey respectively that were used for measuring our variables of interest.

We tried to minimize order effects in the survey by asking first about flood risk perceptions and mitigation, and later the actual decisions and experiences. Yet, the first questions may bias the response to questions about the role that flood risk has played in the purchase or selling decision. Hence, respondents could potentially overstate the importance of flood risk in their decisions, in particular those that have a high risk perception. This may strengthen the signal in our data on the role of flood risk perception in the decisions to adopt protective responses.

We examine four behavioral responses of buyers and three responses of sellers that relate directly to flood risk and how it affects the market value of properties in the flood zone. For buyers: (1) considering flood zones when looking for a property (Part B.4, question 9 in Appendix B), (2) avoiding a property in the flood zones, (3) getting flood insurance on the new property (Part B.3, question 1 in Appendix B), and (4) paying less for properties that are located in a flood zone. For sellers: (1) moving out of the flood zone (Part C.3, question 1 in Appendix C), (2) moving primarily to avoid future hazards (Part C.4, question 1 in Appendix C), and (3) asking for a lower price if the property is within a flood zone.

The tendency to avoid property in the flood zone is measured by combining three questions on a Mokken scale ( $\alpha=0.73$ ): (1) not buying property that has been flooded before (easy), (2) not buying property in the flood zone with an annual 1:100 chance of flooding (intermediate) and (3) not buying property in the flood zone with an annual 1:500 chance of flooding (difficult). The scores are normalized based on the mean score of all respondents on each of the three items, resulting in the average score per respondent.

$X_{i}=\sum_{j=1}^{3}\left(\frac{x_{i j}}{\sum_{i=1}^{N} x_{i j} / N}\right)$

In Eq. (1) $N$ is the number of survey respondents and $x_{i j}$ indicates the score of respondent $i$ on item $j$.

Buyers' willingness to pay for properties in the flood zones is measured by looking at their bid price or purchase price relative to the 
Table 2

Summary statistics of the variables included in the analysis.

\begin{tabular}{|c|c|c|}
\hline Variable & Description; Question \# in survey, Appendices B and C & Rationale \\
\hline \multicolumn{3}{|l|}{ Buyer and seller variables } \\
\hline Fear towards flooding & $\begin{array}{l}\text { Combined score on questions that measure fear towards flooding; } \\
\text { Q2 in Appendix B.2 and Appendix C. } 2\end{array}$ & $\begin{array}{l}\text { The affect heuristic and protection motivation theory state that fear } \\
\text { drives people's perception of risk and can motivate protective as well } \\
\text { as non-protective responses (van Duinen et al., 2015) }\end{array}$ \\
\hline $\begin{array}{l}\text { Information and learning about } \\
\text { flood risk }\end{array}$ & $\begin{array}{l}\text { Sources and ways to get informed about flood risk (personal } \\
\text { experience, family or friends, neighbors, FEMA flood maps, news } \\
\text { media, or other sources); Q1 Appendix B.6 and Appendix C.6 }\end{array}$ & $\begin{array}{l}\text { Various sources of information can dynamically affect (positively and } \\
\text { negatively) people's risk perceptions, fear, and motivation to adopt } \\
\text { protective responses }\end{array}$ \\
\hline Not learning about flood risk & $\begin{array}{l}\text { Indicates whether people are informed about flood risk at all or not; } \\
\text { Q1 Appendix B.6 and Appendix C.6 }\end{array}$ & $\begin{array}{l}\text { Being informed about hazard risks is essential in order to start } \\
\text { considering the benefits of risk management strategies }\end{array}$ \\
\hline Experienced flooding in town & $\begin{array}{l}\text { Indicates whether people have experienced a major flooding event } \\
\text { in their town; Q1 Appendix B.5 and Appendix C.5 }\end{array}$ & $\begin{array}{l}\text { Experience is considered an important source of information on } \\
\text { which people base their perceptions and decisions (Bubeck et al., } \\
\text { 2013) }\end{array}$ \\
\hline Damage from flooding & $\begin{array}{l}\text { Indicates whether people have experienced any damages from a } \\
\text { flooding event; Q4 Appendix B.5 and Appendix C.5 }\end{array}$ & $\begin{array}{l}\text { Damage, as an indicator of bad experience, can enhance people's fear } \\
\text { towards the risk according to the affect heuristic theory (Van } \\
\text { Duinen et al., 2015) }\end{array}$ \\
\hline Probability of flooding & $\begin{array}{l}\text { Indicates whether a property (bought or sold) is in a flood zone, and } \\
\text { in which flood zone, to the knowledge of the respondents; Q8 } \\
\text { Appendix B.4 and Q12 Appendix C. } 4\end{array}$ & $\begin{array}{l}\text { In expected utility theory the objective probability of a flood forms } \\
\text { the base of people's perceived probability and hence their risk } \\
\text { perception }\end{array}$ \\
\hline Perceived likelihood of damage & $\begin{array}{l}\text { Indicates the perceived likelihood that their property will get } \\
\text { damages from flooding; Q1 Appendix B.2 and Appendix C.2 }\end{array}$ & $\begin{array}{l}\text { This variable can elicit the function by which people value the } \\
\text { objective probability of flood under prospect theory (Lindel and } \\
\text { Hwang, 2008; van Duinen et al., 2015; Trumbo et al., 2014) }\end{array}$ \\
\hline \multicolumn{3}{|r|}{ 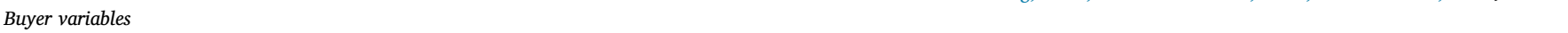 } \\
\hline $\begin{array}{l}\text { Take flood risk into account in the } \\
\text { search for a home }\end{array}$ & $\begin{array}{l}\text { Buyers who have thought about flood zones when they started } \\
\text { looking for a property; Q9 Appendix B.4 }\end{array}$ & $\begin{array}{l}\text { Before even considering how to deal with the risk of flooding, buyers } \\
\text { first need to take the risk into consideration }\end{array}$ \\
\hline Avoid flood zones & $\begin{array}{l}\text { Average score on the statement 'If a property was in a ... flood zone } \\
\text { (or flooded before), I would never buy this property'; Q2 Appendix } \\
\text { B. } 2\end{array}$ & $\begin{array}{l}\text { Dependent variable to measure whether risk perception and fear } \\
\text { actually lead to a protective response in the form of risk avoidance }\end{array}$ \\
\hline Willingness to pay (\%) & $\begin{array}{l}\text { Buyers' bid price or transaction price relative to the listing price } \\
\text { when buyers placed their first offer; Q1 and Q2 Appendix B. } 4\end{array}$ & $\begin{array}{l}\text { In expected utility theory the expected costs of the risk should equal a } \\
\text { reduction in the willingness to pay }\end{array}$ \\
\hline Get flood insurance & $\begin{array}{l}\text { Preparedness to get flood insurance on the new home; Q1 Appendix } \\
\text { B.3 }\end{array}$ & $\begin{array}{l}\text { Dependent variable to measure whether the perceived risk leads to a } \\
\text { protective response in the form of flood insurance (van Duinen et al., } \\
\text { 2015; Bubeck et al., 2013) }\end{array}$ \\
\hline $\begin{array}{l}\text { Perceived costs of mitigation } \\
\text { measure }\end{array}$ & $\begin{array}{l}\text { Perceived costs of various risk mitigation measures (get flood } \\
\text { insurance, install flood vents, selling the house and move out of the } \\
\text { flood zone, elevating the property and abandon the lowest flood); } \\
\text { Q3 Appendix B.3 }\end{array}$ & $\begin{array}{l}\text { Protection motivation theory variable that is part of people's cost- } \\
\text { effectiveness evaluation of the mentioned risk management strategies } \\
\text { (van Duinen et al., 2015; Bubeck et al., 2013) }\end{array}$ \\
\hline $\begin{array}{l}\text { Perceived effectiveness of } \\
\text { mitigation measure }\end{array}$ & $\begin{array}{l}\text { Perceived effectiveness of various risk mitigation measures (get } \\
\text { flood insurance, install flood vents, selling the house and move out } \\
\text { of the flood zone, elevating the property and abandon the lowest } \\
\text { floor); Q2 Appendix B.3 }\end{array}$ & $\begin{array}{l}\text { Protection motivation theory variable that is part of people's cost- } \\
\text { effectiveness evaluation of the mentioned risk management strategies } \\
\text { (van Duinen et al., 2015; Bubeck et al., 2013) }\end{array}$ \\
\hline Adopt protective measures & $\begin{array}{l}\text { Preparedness to adopt any protective measures to reduce damage } \\
\text { from flooding (installing flood vents, elevating the property or } \\
\text { abandoning the lowest floor); Q1 Appendix B.3 }\end{array}$ & $\begin{array}{l}\text { Dependent variable to measure whether the perceived risk leads to a } \\
\text { protective response in the form of structural modifications to the } \\
\text { property (van Duinen et al., 2015; Bubeck et al., 2013) }\end{array}$ \\
\hline \multicolumn{3}{|r|}{$\begin{array}{l}1 \\
\end{array}$} \\
\hline $\begin{array}{l}\text { 100-year flood zone AND } \\
\text { experienced flooding in town }\end{array}$ & $\begin{array}{l}\text { Indicates sellers of property in the } 100 \text {-year flood zone who have } \\
\text { experienced a flood in their town; Q12 Appendix C. } 4 \text { and Q1 } \\
\text { Appendix C.5 }\end{array}$ & $\begin{array}{l}\text { Floods have a high impact in the } 100 \text {-year flood zones, which will } \\
\text { negatively impact the value of a property }\end{array}$ \\
\hline $\begin{array}{l}\log (\$) \text { willingness to accept for } \\
\text { property }\end{array}$ & $\begin{array}{l}\text { Transaction price of recently sold property or current list price of } \\
\text { property still on the market on a log scale; Q3 Appendix C. } 4\end{array}$ & $\begin{array}{l}\text { In expected utility theory the expected costs of the risk should be } \\
\text { discounted by sellers in the form of a willingness to accept }\end{array}$ \\
\hline Moving out of the flood zone & $\begin{array}{l}\text { Sellers who have moved away from the flood zone after selling their } \\
\text { property; Q1 Appendix C.1 }\end{array}$ & $\begin{array}{l}\text { Dependent variable to measure whether risk perception and fear lead } \\
\text { to future risk avoidance }\end{array}$ \\
\hline $\begin{array}{l}\text { Moving out to avoid future } \\
\text { hazards }\end{array}$ & $\begin{array}{l}\text { Sellers who explicitly mentioned that the risk of natural hazards was } \\
\text { a reason to sell their property; Q1 Appendix C. } 4\end{array}$ & $\begin{array}{l}\text { Moving away from the flood zone may be directly related to risk } \\
\text { avoidance behavior }\end{array}$ \\
\hline Costs of flood insurance & $\begin{array}{l}\text { Perceived costs of flood insurance only for those households that } \\
\text { had flood insurance on the property they sold. The value ranges 1-5, } \\
\text { or } 0 \text { otherwise; Q3 Appendix C.3 }\end{array}$ & $\begin{array}{l}\text { Moving away from the flood zone may be related to the costs of } \\
\text { mandatory flood insurance rather than risk perception }\end{array}$ \\
\hline Costs of moving & $\begin{array}{l}\text { Perceived costs of the measure to sell the property and move away } \\
\text { from the flood zone; Q3 Appendix C.3 }\end{array}$ & $\begin{array}{l}\text { The perceived costs of moving, falling under protection motivation } \\
\text { theory, may inhibit people to sell and move away from the flood zone }\end{array}$ \\
\hline $\begin{array}{l}\text { Perceived effectiveness of moving } \\
\quad \text { to reduce risk }\end{array}$ & $\begin{array}{l}\text { Perceived effectiveness of the measure to sell the property and move } \\
\text { away from the flood zone as a way to minimize future damages from } \\
\text { flooding; Q2 Appendix C.3 }\end{array}$ & $\begin{array}{l}\text { Falling under protection motivation theory, the perceived } \\
\text { effectiveness of reducing the hazard exposure by moving away from } \\
\text { the flood zone may motivate people to relocate (van Duinen et al., } \\
\text { 2015; Bubeck et al., 2013) }\end{array}$ \\
\hline
\end{tabular}

listing price (in \%) at the time of bidding, and can be negative or positive depending on whether buyers bid under or over ask price respectively. We ask buyers to give both values because we know that buyers typically anchor their bids on the sellers' ask price. Therefore, there is no need to control for various housing characteristics which is common practice in hedonic studies that measure the marginal contribution of various housing attributes to the sales price of properties on the market, such as a discount for properties that are prone to flooding. We compare the offers for properties outside a flood zone with those inside a flood zone. We ask the respondents to inform us whether the property they bought (or are considering buying) is located inside any flood zone, and about the annual probability of flooding for these flood zones, regardless of whether this information is correct or known to the buyer. Primarily because our interest is in homeowners' responses to their perception of flood risk rather than objective information of flood risk.

Similarly, we measure if location in a flood zone affects sellers' ask price for properties. This requires more information about the 
properties to control for various structural and spatial characteristics, which is typical in any hedonic study of housing prices (Rosen, 1974). We take into account square footage, whether a property is located on the waterfront, presence of a garage and Zillow Home Value Index (Zillow, 2018). The latter is a spatial measure of housing values that controls for the market where the property is sold. For example: the median value of a property in Miami (FL) is twice as much as the mean value of a property in Jacksonville (FL). Hedonic studies commonly use a lot more variables than just housing prices, but these studies often have a lot more data available both in number of transactions and in number of housing attributes. We choose to limit the number of variables to prevent overloading the respondents with detailed questions on housing attributes, and to prevent over-parameterizing our model (De Koning et al., 2018).

Additionally, we are interested in homeowners' perceived likelihood that flooding can cause damage to their property. This is only partly affected by the objective knowledge of being located in a flood zone and may be much more important in governing decisions in the market. We measure the perceived likelihood of damages on a qualitative scale: "How likely is it that your house will get damage from flooding?" answered on a 4 point scale with end labels 1 = "very unlikely" and 4 = "very likely". Despite numerous attempts to measure perceived probabilities on a quantitative scale (Botzen et al., 2009; Katapodi et al., 2004; Weinstein, 2000) we decide that it is better to avoid this line of questioning for the following reasons: people find it difficult to understand probability statistics, people find it hard to express their perceived probabilities, the answers that people give are anchored on what the options are, and qualitative assessments are often better predictors than quantitative ones (Weinstein et al., 2007).

Finally, we measure people's fear towards flooding, which is treated as separate risk perception variable in the psychometric paradigm (Slovic et al., 2004) and protection motivation theory (Grothmann and Reusswig, 2006). This variable combines the scores of two questions that measure fear $(\alpha=0.77)$ (Part B.2, question $2 \mathrm{~g}$ and $2 \mathrm{~h}$ in Appendix B), and is calculated in the same way as Eq. (1).

Apart from the behavioral responses that relate to location choice and willingness to pay/willingness to accept for properties at risk, we enquire about a few alternatives that reduce households' flood risk in case they live in a flood zone. We select a few options suggested by the Federal Emergency Management Agency (FEMA) that have a high potential in reducing damage from flooding (FEMA, 2015), namely: installing flood vents/openings (routes for the water to drain), elevating the property, and abandoning the lowest floor. We measure all coping appraisal variables of protection motivation theory related to these options: protective response efficacy (i.e. how effective do you think this measure is in reducing your risk?), perceived self-efficacy (i.e. how easy or difficult do you think it is to adopt this measure in your home?) and perceived response costs. The same is measured for the options to get flood insurance and to sell the property and move away from the flood zone.

\subsection{Statistical analyses - Bayesian statistics}

The above mentioned variables on the risk perception and mitigation behavior and their relation are selected using a number of explanatory variables that we consider relevant in affecting risk perceptions and mitigation behavior. Table 3 provides an overview of the dependent variables (first column) and the variables that are used to predict them (second column). Next, we run a stepwise regression with backward selection based on the Akaike information criterion in order to select those variables that are significant in explaining the dependent variable. We also check the signs of the coefficients to evaluate whether the outcome of the stepwise regression analysis makes sense.

The models with the lowest number of informative explanatory variables are used to construct Figs. 1 and 2. We use the Bayesian approach to support the evidence for the causal relationships between the variables depicted in Figs. 1 and 2 (Howson and Urbach, 2006). We apply Bayesian statistics as an addition to the stepwise regressions that yield $p$-values of the coefficients. Bayesian statistics is used to assess the likelihood of a certain hypothesis given the available data, $p(\mathrm{H} \mid$ data), whereas the frequency statistics yield the likelihood of the data given a certain hypothesis, $p($ data $\mid \mathrm{H})$. More specifically, $p$-values used in frequency statistics indicate the likelihood of the data given the null-hypothesis (i.e. there is no causal relationship or correlation between the tested variables), $p\left(\right.$ data $\left.\mid \mathrm{H}_{0}\right)$, and can subsequently lead to the rejection of this null-hypothesis. The problem with this frequentist approach is that it can result in type-I and type-II errors, i.e. false rejection of the null-hypothesis or failure to reject the false null-hypothesis. The benefit however of using the Bayesian approach is that it allows for simultaneously assessing the likelihood of a set of alternative hypotheses, including the null hypothesis, based on the available data and a set of prior likelihoods of combinations of hypotheses and data. Instead of an arbitrary cut-off value (typically: $\alpha=0.05$ ) that leads to the rejection of a hypothesis, Bayesian statistics can yield a likelihood estimation that a certain hypothesis is true without having to falsify any alternative hypothesis. This hypothesis can for example be about the value of a certain parameter in a regression model. As Ellison (2004) phrases: "Bayes' Theorem provides an intuitively clear alternative method for estimating parameters and expressing the degree of confidence or uncertainty in those estimates. Bayesian methods allow for the explicit incorporation of as much or as little existing data or prior knowledge that is available and provides a direct measure of the probability of one or more hypotheses of interest."

The Bayesian approach forces the researcher to be explicit in the prior assumptions about the hypotheses and the data, and specify the prior likelihood of one or more hypotheses. At this stage it can be decided a priori that certain hypotheses are more likely than others, which is not accounted for in frequency statistics. These priors can be derived from earlier studies, so that each new study adds knowledge to the previous one, which builds increasing evidence and confidence in supporting a particular hypothesis with every new study. The list of priors used for this study is summarized in Table 4 (Appendix A). The priors for sellers' ask price and buyers' willingness to pay are derived from a meta-analysis of hedonic studies that assesses how flood risk affects the value of properties in the flood zones (Beltrán et al., 2018). The prior likelihood of the effect size is a normal distribution, which means that the effect size, a priori, is most likely the mean of all hedonic studies on flood risk and property values. For all other variables we use uninformative priors, i.e.: the true effect could be any value between a certain range with an equal likelihood for each value within this range, which is a uniform distribution between a minimum and a maximum.

For each relation between the variables we form a set of mutually exclusive hypotheses:

H0. There is no effect between the independent and dependent variable.

Ha1. The independent variable has a negative effect on the dependent variable.

Ha2. The independent variable has a positive effect on the dependent variable.

These hypotheses meet two conditions: (1) They are mutually exclusive, i.e.: $p\left(\mathrm{H}_{0} \cup \mathrm{H}_{\mathrm{a} 1} \cup \mathrm{H}_{\mathrm{a} 2}\right)=p\left(\mathrm{H}_{0}\right)+p\left(\mathrm{H}_{\mathrm{a} 1}\right)+p\left(\mathrm{H}_{\mathrm{a} 2}\right)$. (2) They cover the full range of all possible outcomes, i.e.: $p\left(\mathrm{H}_{0}\right)+p\left(\mathrm{H}_{\mathrm{a} 1}\right)+p$ $\left(\mathrm{H}_{\mathrm{a} 2}\right)=1$. Furthermore, we allow for a certain range of negligible effect sizes around $\mathrm{H}_{0}$, which increases the likelihood of $\mathrm{H}_{0}$, whereas it is nearly impossible to find an effect size that is exactly equal to 0 . We neglect effect sizes smaller than 0.10 times the standard deviation of the dependent variable, which falls in the range of $\mathrm{H}_{0}$. Any effect sizes larger than 0.10 times the standard deviation of the dependent variable fall in the range of $\mathrm{H}_{\mathrm{a} 1}$ or $\mathrm{H}_{\mathrm{a} 2}$. The posterior probabilities of $\mathrm{H}_{0}, \mathrm{H}_{\mathrm{a} 1}$ and $\mathrm{H}_{\mathrm{a} 2}$ are calculated as follows: 
Table 3

List of explanatory variables and dependent variables included in the stepwise regression.

\begin{tabular}{|c|c|}
\hline Dependent variables & Explanatory variables considered \\
\hline Fear towards flooding & $\begin{array}{l}\text { Learning about floods through FEMA, learning about floods through neighbors, learning about floods through family } \\
\text { and friends, learning about floods through news media, not learning about flood risk, damage from flooding, } \\
\text { experienced flooding in town, probability of flooding, perceived likelihood of damage }\end{array}$ \\
\hline $\begin{array}{l}\text { Install flood vents, elevate the property, abandon the } \\
\text { lowest floor }\end{array}$ & $\begin{array}{l}\text { Perceived costs of mitigation measure, perceived effectiveness of mitigation measure, perceived self-efficacy of } \\
\text { mitigation measure, fear towards flooding, perceived likelihood of damage }\end{array}$ \\
\hline Avoid flood zone & $\begin{array}{l}\text { Perceived costs of moving, perceived effectiveness of moving, perceived self-efficacy of moving, fear towards flooding, } \\
\text { perceived likelihood of damage, probability of flooding }\end{array}$ \\
\hline Get flood insurance & $\begin{array}{l}\text { Perceived costs of flood insurance, perceived effectiveness of flood insurance, perceived self-efficacy of flood insurance, } \\
\text { fear towards flooding, perceived likelihood of damage, take flood risk into account in the search for a home }\end{array}$ \\
\hline Take flood risk into account in the search for a home & $\begin{array}{l}\text { Learning about floods through neighbors, learning about floods through family and friends, learning about floods } \\
\text { through news media, not learning about flood risk, damage from flooding, experienced flooding in town }\end{array}$ \\
\hline Perceived likelihood of damage (buyer) & $\begin{array}{l}\text { Learning about floods through neighbors, learning about floods through news media, not learning about flood risk, } \\
\text { damage from flooding, experienced flooding in town, probability of flooding }\end{array}$ \\
\hline $\log (\$)$ willingness to accept for property & $\begin{array}{l}\text { Square footage (log), house on the waterfront, house with a garage, Zillow home value index, } 100 \text {-year flood zone AND } \\
\text { experienced flooding in town, } 500 \text {-year flood zone AND experienced flooding in town, damage from flooding, } \\
\text { experienced flooding in town, } 100 \text {-year flood zone dummy, } 500 \text {-year flood zone dummy, perceived likelihood of } \\
\text { damage }\end{array}$ \\
\hline Moving out of the flood zone & $\begin{array}{l}\text { Perceived costs of moving, perceived effectiveness of moving, get flood insurance, get flood insurance AND perceived } \\
\text { costs of flood insurance, fear towards flooding, perceived likelihood of damage, damage from flooding }\end{array}$ \\
\hline Moving out to avoid future hazards & $\begin{array}{l}\text { Perceived costs of moving, perceived effectiveness of moving, fear towards flooding, perceived likelihood of damage, } \\
\text { damage from flooding }\end{array}$ \\
\hline Perceived likelihood of damage (seller) & $\begin{array}{l}\text { Learning about floods through FEMA, learning about floods through neighbors, learning about floods through family } \\
\text { and friends, learning about floods through news media, not learning about flood risk, perceived likelihood of damage, } \\
\text { fear towards flooding, damage from flooding, experienced flooding in town, probability of flooding }\end{array}$ \\
\hline
\end{tabular}

$p(\mathrm{H} \mid$ data $)=\frac{p(\mathrm{H})^{*} p(\text { data } \mid \mathrm{H})}{p(\text { data })}=\frac{p(\mathrm{H})^{*} p(\text { data } \mid \mathrm{H})}{\int_{\min }^{\max } p(\mathrm{H})^{*} p(\text { data } \mid \mathrm{H}) \mathrm{dH}}$

$\int_{\min }^{\max } p(\mathrm{H}) \mathrm{dH}=1$

$p(\mathrm{H}) \ni p\left(\mathrm{H}_{0}\right), p\left(\mathrm{H}_{\mathrm{a} 1}\right), p\left(\mathrm{H}_{\mathrm{a} 2}\right)$

$p(\mathrm{H})$ in Eqs. (2)-(4) is the function that describes the prior probability density of the effect size, which is a continuous probability function of all possible effect sizes, the sum of which equals to 1 (Eq. (3)). For computational purposes we limit these to 10,001 discrete hypotheses between a predefined minimum and maximum. $p($ data $\mid \mathrm{H})$ in Eq. (2) is the probability density of our data for each hypothesis (note that the specific case of $p\left(\right.$ data $\left.\mid \mathrm{H}_{0}\right)$ in Eq. (2) is the $p$-value yielded from $t$-tests, ANOVAs and regression analyses), $p$ (data) is the weighed probability of the data for all hypotheses, and $p(\mathrm{H} \mid$ data $)$ is the posterior probability density function of the hypotheses. The latter is used to calculate the likelihood of each of the hypotheses $\mathrm{H}_{0}, \mathrm{H}_{\mathrm{a} 1}$ and $\mathrm{H}_{\mathrm{a} 2}$, by assessing

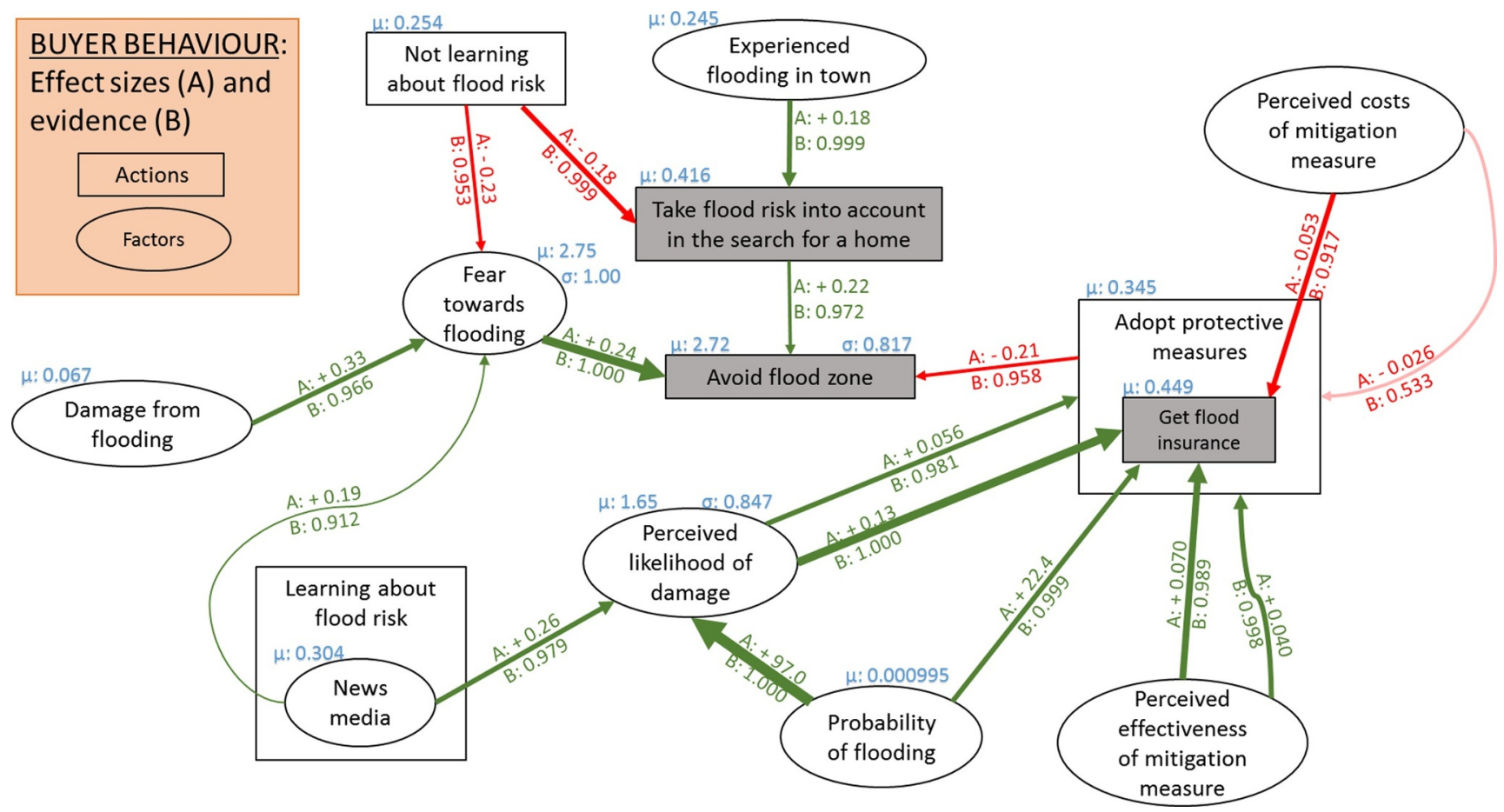

Fig. 1. Impacts and effect sizes (A) of factors that govern buyers' responses to flood risk. B highlights the Bayesian posterior likelihood of the effect. Red indicates negative effects and green the positive. Lighter arrows indicate weaker evidence for the effect. We added the mean value of each variable $(\mu)$ and, if applicable, the standard deviation $(\sigma)$ that allow for a more meaningful interpretation of the effect size. Thicker lines indicate a stronger effect. (For interpretation of the references to color in this figure legend, the reader is referred to the web version of this article.) 


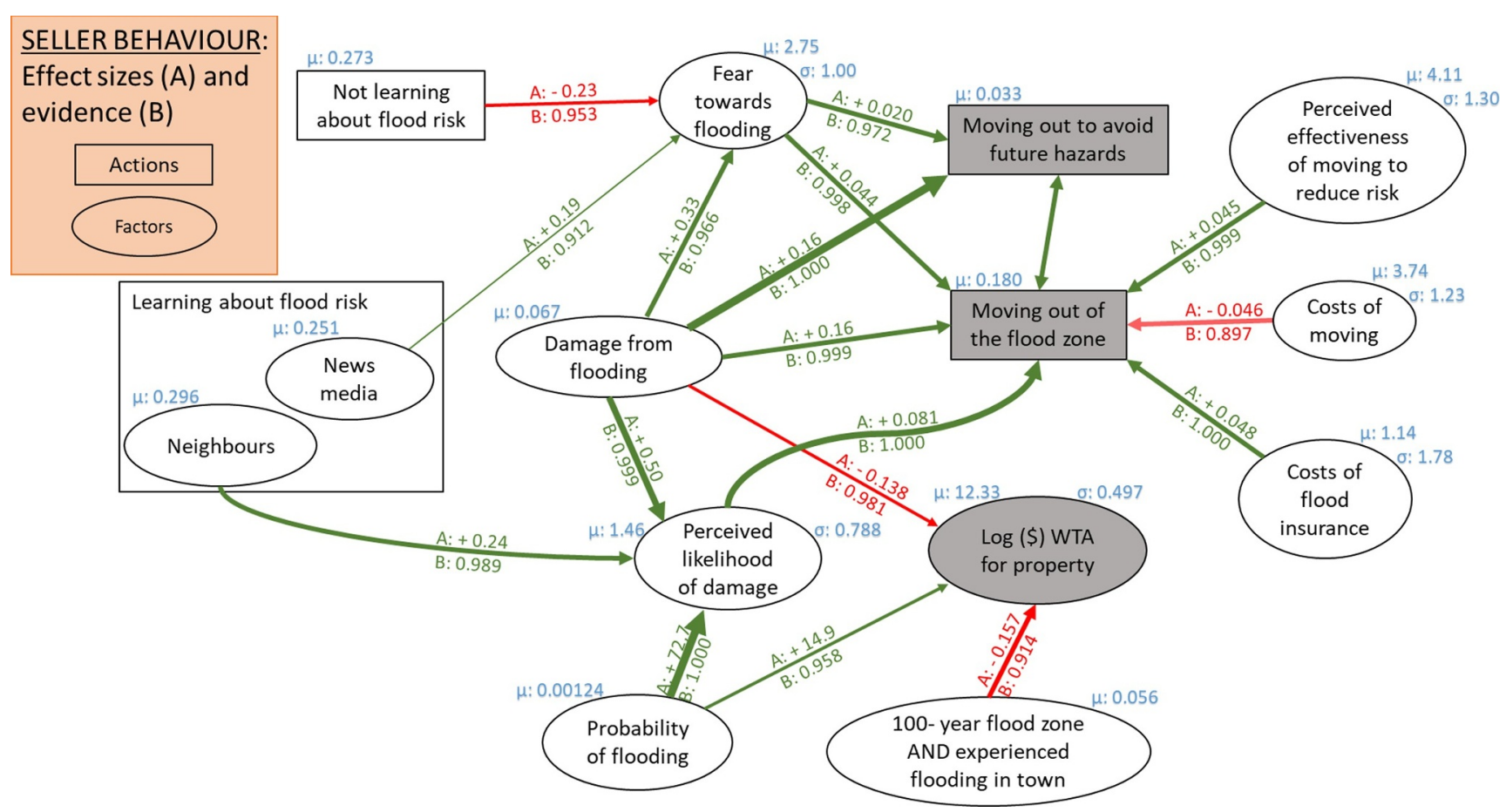

Fig. 2. Impacts and effect sizes (A) of factors that govern sellers' responses to flood risk. B highlights the Bayesian posterior likelihood of the effect. Red indicates negative effects and green the positive. We added the mean value of each variable $(\mu)$ and, if applicable, the standard deviation $(\sigma)$ that allow for a more meaningful interpretation of the effect size. Thicker lines indicate a stronger effect. The main dependent variables are highlighted in gray. The box 'moving out of the flood zone' indicates people that sell their property for all sorts of reasons, and choose to live outside the flood zone after the move. The box 'moving out to avoid future hazards' is a subset of the former group that do so explicitly to escape the hazard of flooding. (For interpretation of the references to color in this figure legend, the reader is referred to the web version of this article.)

which hypothesis $\mathrm{H}$ belongs to which subset in Eq. (4) $\left(\mathrm{H}_{0}, \mathrm{H}_{\mathrm{a} 1}\right.$ or $\left.\mathrm{H}_{\mathrm{a} 2}\right)$ and summing the probabilities $p(\mathrm{H})$ for each subset.

Besides the mean and the range of possible effect sizes, we formed some additional underlying assumptions about the data. First, we assume a priori that the probabilities of the dependent variables in the data follow either a normal or binomial distribution. Second, we assume that the impact on the dependent variable is always linear. We acknowledge that this may not always be the case, but it is sufficient for the purpose of highlighting either a positive or negative relationship between the independent and dependent variable.

\section{Results}

\subsection{Cognitive and affective drivers of households' responses to flood risk}

In our study we find that fear towards flooding, damages from flooding and perceived likelihood of damage are the three main factors that drive households' responses to flood risk. For buyers these responses are: considering flood zones when looking for a property, avoiding property in the flood zones, and getting flood insurance on the new property. For sellers the responses are: moving out of the flood zone, ${ }^{3}$ and accepting a lower price for their property if it is in a flood zone. Figs. 1 and 2 show all the relevant relations between risk perception variables, experience, information and learning and their effect on the decisions to either self-protect against flooding or to avoid the hazard. The strength of the effect is highlighted by the thickness of the lines, the darkness of the lines indicates the strength of the evidence for the hypothesized effect $\left(\mathrm{H}_{\mathrm{a}}\right)$, and colors indicate whether the response

\footnotetext{
${ }^{3}$ A certain group of people were living in the flood zone and decided to sell their house for various reasons, while they were looking for a new home outside the flood zone. A subgroup of these people decided to abandon the flood zone explicitly because of the risk of natural hazards.
}

was positive or negative $\left(\mathrm{H}_{\mathrm{a} 1}\right.$ or $\left.\mathrm{H}_{\mathrm{a} 2}\right)$. Fear, driven by (lack of) information and experience, is the main reason for buyers to avoid the flood zone (Fig. 1), with an effect size of 0.97 standard deviation. ${ }^{4}$ While the adoption of other protective responses (in particular flood insurance) is primarily driven by the perceived likelihood of damage (effect size of 0.78 standard deviation in the case of purchasing flood insurance), and to a lesser extent by other cognitive decision processes and variables included in protection motivation theory. On the seller's side we see that the decision to move out of the flood zone is a combination of affective as well as cognitive decision processes, though this includes people that sell their house for different reasons than flood risk alone. People who sell their house explicitly to avoid the risk of natural hazards do so for affective reasons: fear and experience with flood damage (effect sizes of 0.37 and 0.90 standard deviation respectively). Experience with flooding in town and damage to property are the only factors that reduced sellers' ask price for properties in the 1:100 annual flood zone. The probability of flooding has a positive effect on the ask price, which may be counter-intuitive, but is actually a very common finding because properties at high risk of flooding are often associated with high environmental amenities such as living close to the beach or living close to water (Bin et al., 2008).

In Fig. 2 we exclude sellers' protective measures against flooding, even though we find the same factors to be relevant in their decisions to self-protect against flooding as in the buyer survey. Yet, for sellers the adoption of protective measures against flooding has no further consequences for their decision to sell their property, which means moving out of the flood zone.

These results show that affective decision-making drives buyers to avoid the flood zone and sellers to abandon their homes at risk of

\footnotetext{
${ }^{4}$ The effect size depends on the coefficient of the linear regression, the range (min-max) of the independent variable and the standard deviation of the dependent variable.
} 
flooding. For buyers the effect of fear is almost four times stronger than the cognitive processes of thinking about flood risk when searching for a property and the adoption of measures to reduce the risk of flooding. Also for sellers, fear and experience with damage are the only drivers we found that cause them to abandon the flood zone by selling their property. Damage from flooding is particularly impactful, making it almost five times more likely for homeowners to abandon the flood zone by selling their property. An increase in fear could also easily double this likelihood. The decisions to adopt protective measures against flooding are more objective, and are influenced by the perceived likelihood of damage, perceived control efficacy and perceived control costs. For example, the intention to get flood insurance is positively affected by perceived control efficacy of flood insurance, the perceived costs of flood insurance and the actual probability of flooding. The latter is most likely caused by the fact that flood insurance in the U.S. is mandatory for properties in the 1:100 annual flood zone that are financed by a federally insured mortgage.

Sellers that move out of the flood zone do so for various reasons, ranging from cognitive appraisals of costs, risks and effects to affective responses such as experience and fear. It should be noted that sellers who move out of the flood zone do not always do so explicitly because of the risk. They may initially have different reasons to sell their house, but in the process, they also decide to avoid the flood zone in their future home. The choice could also be to avoid the costs of flood insurance, and thus made independent of flood risk. Only a small proportion of respondents (3.3\%) explicitly mention that their reason to sell is to avoid the risk of flooding.

\subsection{Which information drives perceptions}

News media and personal experience are the primary information sources that affect feelings of fear for both sellers and buyers. Fear is positively affected by experience with damage from flooding and to some extent also by the news media, though this effect is rather small ( \pm 0.19 standard deviation). The Bayesian posterior likelihoods of these positive effects are $96.6 \%$ and $91.2 \%$ respectively based on the survey data (Figs. 1 and 2), and the effect of damage on fear is 1.7 times larger than media on fear. People who are uninformed about flood risk have a lower fear towards flooding $(-0.23$ standard deviation), implying that a lack of information about a hazard reduces fear towards it. Consequently, these buyers do not take flood zones into account in their choice on where to buy property. Buyers that experience a flooding event in their town are more likely to take flood zones into account. It does not affect their level of fear, likely because not everyone who experiences flooding in their town regards it as a dreadful experience. Furthermore, taking the flood zones into account in the choice on where to buy property is somewhat related to the tendency to avoid the flood zones altogether, but it is not a one-to-one correlation. We did not ask for more details about what their considerations are about the flood zones, apart from avoiding them. Perhaps these are also related to other protective measures, or even to the positive aspects of living in flood zones (e.g. living close to the beach or on the waterfront). We do not take these measures into account in our analysis.

The perceived likelihood of damage is to a large extent governed by objective information on the probability of flooding, i.e. the knowledge that a house is in the flood zone. Interestingly, information from neighbors affected the perceived likelihood of damage for sellers, and buyers' perceived likelihood of damage was influenced by news media. Neighbors' experience with flooding as well as personal damages has a positive effect on sellers' perceived likelihood of damage. Experience and interaction with neighbors affect sellers' risk perception because they have been resident in the flood zone. While buyers, who are the newcomers to the area, are more influenced by information from news media and not by their own experience or experience from neighbors.

\subsection{Effects on property values in hazard areas}

Given that flood risk influences the decisions that buyers make in the market in terms of avoiding the flood zones, it is expected that sellers in the flood zones anticipate on this by lowering their ask price. Similarly, we expect that buyers offer a lower price for a property in the flood zone. We do find such an effect for sellers who have experienced a flood, in particular those that have had damage from flooding, but not for buyers. Buyers' willingness to pay is unaffected by flood risk, probably because the risk-sensitive buyers are already sorted out by avoiding the flood zones. On average, sellers in the flood zones demand a higher price for their property, unless their town is hit by a major flooding event or their property is damaged by flooding. A higher price for properties in the flood zones is found in many hedonic pricing studies that valuate the risk of flooding (e.g. Bin and Kruse, 2006; Bin et al., 2008; Hallstrom and Smith, 2005), and is likely caused by positive amenities associated with flood zones. It is likely that sellers in the 1:100 annual flood zone anticipate on a drop in demand after a major flooding event, causing them to drop their price. However, the evidence for this effect is only a little over $91 \%$, which leaves a $9 \%$ probability of a type-I error (false positive). The evidence that direct damages from flooding negatively affect sales prices is higher at $98 \%$.

\section{Discussion and conclusions}

Flood risk is already one of the costliest natural hazards of all, and the impacts are only expected to increase in frequency and severity with climate change. In addition, the severity of flood damage is boosted by an increase in population and capital at stake. This means that flood damage mitigation measures will become more costly and decreasingly effective. Flood insurance will become increasingly costly, both for policy holders as well as for insurance companies in case of a flooding event. Therefore, a complimentary strategy that contributes to societal resilience against ever-growing flood risks is to retreat from hazardous areas (Dronkers et al., 1990). Retreat can take a form of a governmental planned policy or be triggered from the bottom up by individuals' motivation to move. We assess to what extent households are prepared to protect themselves against flooding by taking precautionary action, as well as their choice whether to live in a flood-zone. The former has been well studied in numerous surveys, in particular, what drives homeowners' preparedness to self-protect against flooding (Terpstra, 2011; Zaalberg et al., 2009; Osberhaus, 2017), while the latter has received considerably less attention. Our survey assesses to what extent people who live in the flood zone are prepared to move away from the hazard, and the potential for newcomers to avoid living in a flood zone. We elicit the psychological and cognitive mechanisms that drive these decisions and assess how people respond to information from various sources and measure the impact of prior flood experience. We see that fear and experience with flooding can be important triggers for homeowners to retreat from hazard areas. This implies that bottom-up forces behind the decision to move out (1) are highly sensitive to information that provoke people's feelings of fear inducing volatile responses to flood risk, and (2) rely on hazard events to trigger a protective action, which ideally would take place well before these events occur.

The factors that drive behavioral responses to flood risk are subject to change, driven by new information, personal experience and learning from others. In our study we find one key difference between avoiding and protecting against flood risk in the mechanisms that drive these behaviors. Abandoning and avoiding the flood zones are mostly driven by bad experiences and fear - buyers' fear has almost twice as much impact as other variables combined on the tendency to avoid the flood zones and sellers' decision to abandon the hazard zones is exclusively affected by experience with damage and fear - which fits the psychometric paradigm of affective decision making well (Slovic et al., 2004). The adoption of flood damage mitigation measures is governed by more 
cognitive decision processes that are incorporated in protection motivation theory (Grothmann and Reusswig, 2006). Protection motivation theory is a comprehensive framework that explains how people adapt to the increasing risk of flooding and has a strong empirical basis. The influence of risk, coping appraisals, and prior experience with flooding are well studied for their effect in motivating households' to take precautionary measures against flooding (Terpstra, 2011; Poussin et al., 2014; Zaalberg et al., 2009; Osberghaus, 2017). Given the previous work that has been done, we restrain from running an extensive analysis on all the variables that drive flood risk damage mitigation measures. Our results are consistent with the findings that perceived probability of damage and perceived costs and effectiveness of flood damage mitigation measures motivate the adoption of precautionary measures against flood damage. However, when it comes to more radical measures to reduce flood risk, i.e. moving out of a flood zone and/ or selling one's flood-prone home, we see that the behavioral drivers shift from risk and response appraisal to fear. The latter is expected to be particularly relevant when hazard events occur more frequently and when more people experience flooding first-hand.

Our primary concern is the different decision-making processes between location choice and adopting flood damage mitigation measures, i.e.: moving out of a flood zone and protecting against flood damage in a flood-prone location. Furthermore, we tested if there is any interaction between the two. Results indicate that fear and bad experience (severe damage from flooding) drive people away from hazard areas regardless whether they have taken damage mitigation measures to reduce their personal damage from flooding. Buyers' first decision is whether or not to move out of a flood zone in their search for a new home. The choice on how to best protect themselves against flooding is a secondary decision. It appears that buyers' preparedness to adopt protective measures against flooding has a slight negative impact on the tendency to avoid flood zones, but the causality could be reversed buyers that avoid the flood zones do not need to adopt any further protective measures against flooding. Therefore, we conclude that the choice whether or not to live in the flood zone is made separate from the choice to adopt flood damage mitigation measures.

These findings raise a question on whether these cognitive mechanisms may cause any structural changes in urbanization in climatesensitive areas in the long run, attenuating or amplifying resilience of these areas. In this study we find a few trends as a result of flooding events: (1) people who experienced damage have an increased level of fear towards flooding, which drives both buyers and sellers away from flood zones, (2) fear is to a small extent also affected by media coverage of flooding events, (3) people who experienced damage from flooding are more likely to move out of the flood zone, regardless of any measures they took to self-protect against flooding, (4) sellers who experienced damage from flooding, as well as sellers in the 1:100 annual flood zone who experienced flooding in their town will demand a lower price for their property. These four mechanisms contribute to a drop in the demand and an increased supply of (damaged) properties in the 1:100 annual flood zone, and subsequently a drop in property values in hazard zones in the wake of a flood. Acknowledging this, our findings suggest that bottom up forces behind aggregated demand and supply for housing in coastal urban areas may gradually change as probability and severity of floods intensify. The price trends in hazard-prone areas have been observed in previous difference-in-differences studies of property values before and after a flood event (Hallstrom and Smith, 2005; Atreya et al., 2012; Bin and Landry, 2013; Daniel et al., 2009; Kousky, 2010). Yet, none of them provide detailed insight in the bottom-up processes that drive these price changes, since they focus on transaction data. We highlight that homeowners' individual climate adaptation strategies may suddenly change when people experience flood, the effects of which will likely ripple through the housing market dynamics. We speculate that there is an increased risk of highly volatile market responses driven by fear and irrational behavior in areas where climate change causes an increase in extreme flood events. In the extreme case, some areas risk large-scale outmigration (Black et al., 2011), which causes a significant drop in property values in high risk zones (Pryce et al., 2011).

Our results have important policy implications. Namely, while avoiding flood zones is an effective way to reduce a households' vulnerability to flooding, we stress that this strategy should be adopted in a smooth transformative manner to prevent migration and market shocks that are driven by extreme events. Instead of repeatedly subsidizing damage to properties, policies could focus on encouraging people to move out of flood zones well before the next major flooding event. These transformations are not always easy to adopt, and will have a particularly high impact in cities that are entirely below base flood elevation. Yet, in many cases this transformation should not be devastating, since small localized differences in elevation make a big difference in flood risk. Flood zones - and river floodplains in particular - are still very local in many cities.

People's choices where to live and how to protect themselves is a complex issue that depend on many factors. We focus on the cognitive drivers of these individual choices. How these choices affect the structure and outlook of coastal cities affected by climate change is a subject for future research. A survey that measures the status quo alone is insufficient to quantify the potential of reaching a 'tipping point'. Further studies are best focused on quantifying the cumulative impacts of the behavioral responses that we found. This study can be used as input to simulate and explore market responses under various scenarios of flood risk in future climate scenarios, in combination with projected climate change impacts in coastal areas.

\section{Acknowledgments}

We are grateful for the financial support provided by the Faculty of Behavioural, Management and Social Sciences (BMS) of the University of Twente, without which this survey would not have been possible. This work was partially funded by the European Research Council (ERC) under the European Union's Horizon 2020 research and innovation program (grant agreement no. 758014 SCALAR). Furthermore, we would like to thank colleagues at the Department of Economics and at the Center for Natural Hazards Research, East Carolina University, for their support with setting up the survey. Finally, we want to thank Dr. Edward Halteman of Survey Design and Analysis for his feedback on the surveys and for his support in data collection.

\section{Appendix A}

Table 4 


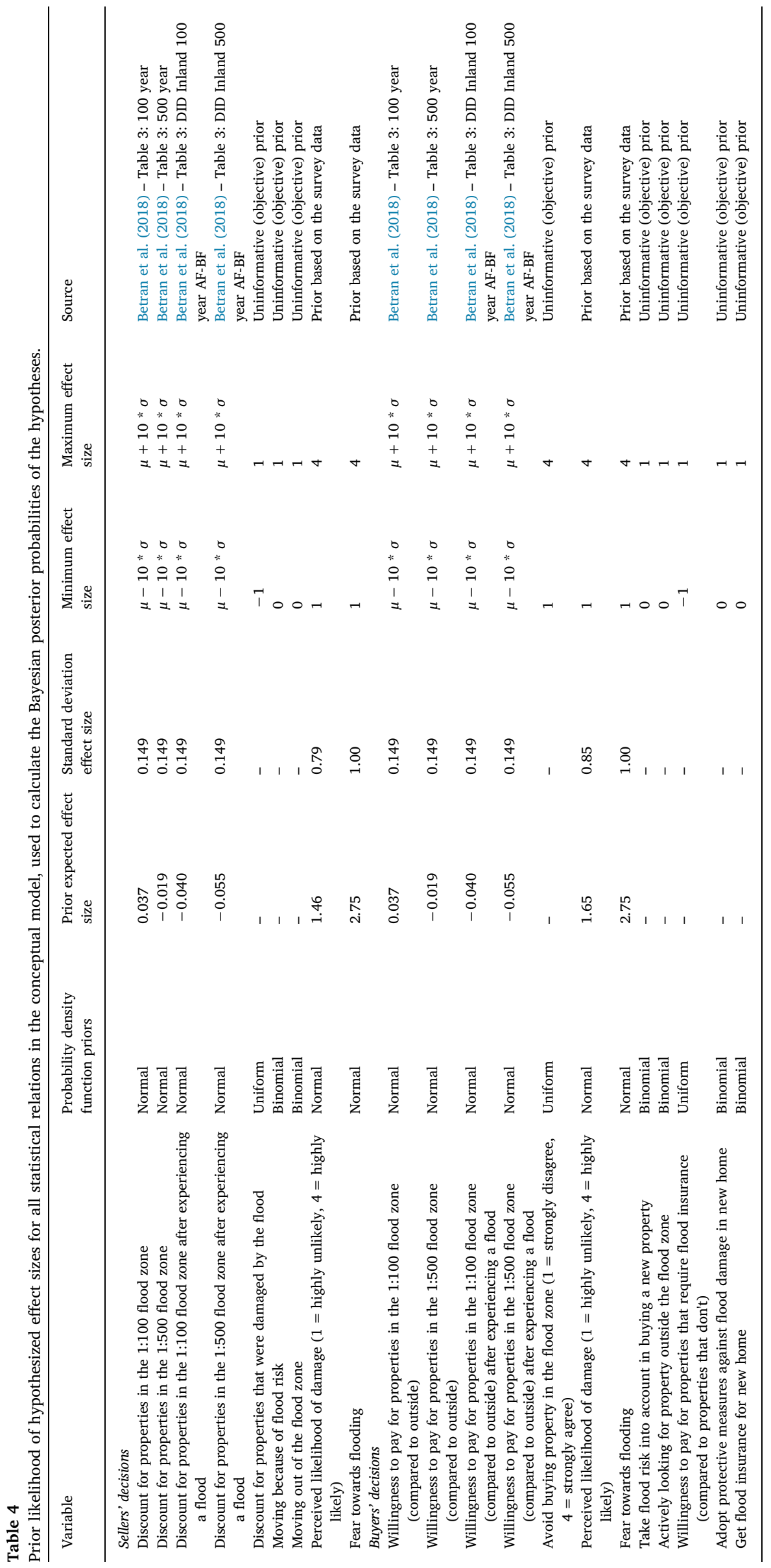




\section{Appendix B. Buyer survey}

Thank you for taking the time to help with our research on flood risk. The information you provide will be used to better understand market forces in housing. The questions should take about 10-15 min of your time.

The questions are divided into five sections:

- Introduction [qualifying questions]

- Flood risk perceptions

- Protection from flood risk

- Your last home purchase

- Experience with flooding

- Demographics

\section{B.1. Introduction [qualifying questions]}

1 In what state do you live?

a [dropdown menu of states]

2 Do you own your own home?

a Yes

b No

3 Did you purchase the home you live in within the past 12 months?

a Yes [proceed to Q6]

b No [proceed to Q5]

4 Are you currently in the market to purchase an owner-occupied house?

a Yes

b No [disqualify and exit survey]

5 Have you identified a property on which you are considering making or have made an offer?

a Yes [proceed to Q7]

b No [disqualify and exit survey]

6 [Screener for current buyers] What interest rate do you expect to pay on your home mortgage?

a $6-7 \%$ [disqualify and exit survey]

b $7-8 \%$ [disqualify and exit survey]

c $8-9 \%$ [disqualify and exit survey]

d 9-10\% [disqualify and exit survey]

e $10-11 \%$ [disqualify and exit survey]

f $>11 \%$ [disqualify and exit survey]

$g$ None of these [proceed with part II of the survey]

7 [Screener for recent buyers] What interest rate are you currently paying on your mortgage?

a $7-8 \%$ [disqualify and exit survey]

b $8-9 \%$ [disqualify and exit survey]

c $9-10 \%$ [disqualify and exit survey]

d $10-11 \%$ [disqualify and exit survey]

e $>11 \%$ [disqualify and exit survey]

$f$ None of these [proceed with part II of the survey]

$\mathrm{g}$ I do not have a mortgage on the house I bought [proceed with part II of the survey]

\section{B.2. Perceptions about flood risk}

Definitions: The Federal Emergency Management Agency (FEMA) identifies flood hazards through statistical information such as data for river flow, storm tides, hydrologic/hydraulic analyses and rainfall and topographic surveys. They outline flood risk areas with certain probabilities of flooding, the 100-year flood zone and 500-year flood zone. They are defined as follows:

500 -year flood zone: The area that has a $0.2 \%$ chance of being inundated by a flood event in any given year.

100-year flood zone: The area that has a $1 \%$ chance of being inundated by a flood event in any given year.

1 [for recent buyers] How likely is it that your house will get damage from flooding?

[for current buyers] How likely is it that the house that you would like to buy will get damage from flooding?

[4-point scale with only end labels: very likely, very unlikely]

1 Please indicate your agreement or disagreement with each of the following statements relating to flood risk using the scale provided.

[4-point scale with only end labels: strongly agree, strongly disagree]

a If a property is in a 100-year flood zone, I would never buy this property

b If a property is in a 500-year flood zone, I would never buy this property 
c If a property has been flooded before, I would not never buy this property

d I'm ok with living in a flood zone

e The risk of flooding deters me from buying property in the (100/500-year) flood zone.

$\mathrm{f}$ The cost of flood insurance deters me from buying property in the 100-year flood zone.

$\mathrm{g}$ I worry about the risk of flooding

$\mathrm{h}$ I fear the consequences of flooding

Space for comments on perceptions of flood risk

\section{B.3. Protecting yourself from flood risk}

1 Which of the following have you done or are you planning to do as ways to minimize your personal damage in case of flooding? (Select all that apply)

a Installation of flood openings (vents), routes for water to drain

b Get flood insurance for your home

c Selling the house and move to a location outside the flood zone

d Elevating your home/Lifting the property or building the house on pilings

e Abandon lowest floor

f None of these

2 Please rate how effective you think each of the following measures is for reducing your risk?

[5-point scale with end labels: very effective/very ineffective + Not sure]

a Installation of flood openings (vents), routes for water to drain

b Get flood insurance for your home

c Selling the house and move to a location outside the flood zone

d Elevating your home/Lifting the property or building the house on pilings

e Abandon lowest floor

1 Please rate how expensive you think each of the following measures is?

[5-point scale with end labels: very expensive/very inexpensive + Not sure]

a Installation of flood openings (vents), routes for water to drain

b Get flood insurance for your home

c Selling the house and move to a location outside the flood zone

$\mathrm{d}$ Elevating your home/Lifting the property or building the house on pilings

e Abandon lowest floor

1 How easy or difficult do you consider these measures be for the home you have bought?

[5-point scale with end labels: very easy/very difficult + Not sure]

a Installation of flood openings (vents), routes for water to drain

b Get flood insurance for your home

c Selling the house and move to a location outside the flood zone

d Elevating your home/Lifting the property or building the house on pilings

e Abandon lowest floor

\section{B.4. Your home purchase}

[for recent buyers] The questions in this section relate to your purchase of the house you now live in. We ask you to remember the process you went through when you bought your house.

[for current buyers] The questions in this section relate to the house you would like to purchase. We ask you to answer these questions about the process you go through related to your purchase.

1 [for recent buyers] How much was the house listed for when you offered the first bid on your house?

[for current buyers] How much is the house currently listed for?

a ___ US dollars

b Don't know

2 [for recent buyers] How much did you pay for your house? 
[for current buyers] How much do you hope to pay for your house?

a ___ US dollars

3 [for recent buyers] Do you currently have a mortgage on the house you purchased?

[for current buyers] Are you planning to have a mortgage on your new home?

a Yes

b No [proceed to Q4]

4 [for recent buyers] What percentage of your purchase price is financed with a commercial broker or bank?

[for current buyers] What percentage of your purchase price are you planning to finance with a commercial broker or bank?

a $76 \%$ or more

b $51-75 \%$

c $26-50 \%$

d $1-25 \%$

e Uncertain/Don't remember

5 Thinking back to when you were looking for a new home, what were your "must have" criteria for purchase?

a No. of bedrooms (please specify)

b A minimum square footage (please specify)

c A minimum number of bathrooms (please specify)

d Within a certain school district

e A garage

f Maximum __ years old (please specify)

g Minimum __ years old (please specify)

$\mathrm{h}$ Acres of land (please specify)

i Live on the water front

j Live near the water

$\mathrm{k}$ Located in certain neighborhood (please specify)

1 House had to be outside the 500 -year flood zone

$\mathrm{m}$ House had to be outside the 100-year flood zone

n Proximity to work (please specify) ___ minutes

o Other (please specify)

p Don't remember

5b. In what price range are/were you looking for a house?

a Upper limit __ US dollars

b Lower limit __ US dollars

6 [for recent buyers] Where did you live prior to purchasing your current home?

[for current buyers] Where do you currently live?

a The same city/area where I live now

b Another city/area in the same state

c In another state (please specify)

d Abroad (i.e. out of the country)

7 [for recent buyers] Please provide the street address and city of your home.

[for current buyers] Please provide the street address and city of the house that you would like to buy.

a Street address:

b City:

c State:

8 [for recent buyers] Is your home in one of the flood zones?

[for current buyers] Is the house you would like to buy in one of the flood zones? 
a Yes, it is in the 500-year flood plain

b Yes, it is in the 100-year flood plain

c Yes, but it's in a different flood zone, namely

$\mathrm{d}$ No, the house is outside of a flood zone [skip Q10 and Q14]

e I don't know [skip Q10 and Q14]

9 Thinking back to when you were looking for a new home, did you think about flood zones at all?

a Yes

b No

10 [for recent buyers] Did the risk of flooding affect the price you paid for the house?

[for current buyers] Does the risk of flooding affect the price you are willing to pay for the house?

a Yes

b No [proceed to Q12]

c Uncertain [proceed to Q12]

11 [if yes] How much would the house be worth if it was not at risk of flooding?

a __ US dollars

b Uncertain

12 [for recent buyers] Do you carry flood insurance on your home?

[for current buyers] Do you plan to get flood insurance on your new home?

a Yes

b No [proceed to Q15]

c Uncertain [proceed to Q15]

13 [for recent buyers] How much are you paying for flood insurance?

[for current buyers] How much do you expect to pay for flood insurance for your new home?

a ___ USD per month

b Uncertain

14 [for recent buyers] Did this flood insurance premium affect the amount you paid for the property?

[for current buyers] Does this flood insurance premium affect the amount you (would) offer for the property?
a Yes
b No
c Uncertain

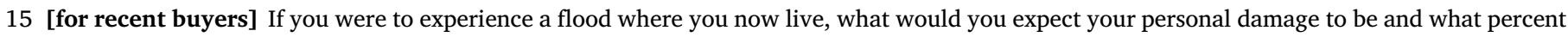
of that total would be covered by insurance?

[for current buyers] If there would be a flood where you are planning to live, what would you expect your personal damage to be and what percent of that total would be covered by insurance?

a Total estimated cost of damages in US dollars__

b Percent of above total covered by insurance

Space for comments on your last home purchase

\section{B.5. Experience with flooding}

1 Did you ever personally experience a major flooding event in your town?

a Yes

b No [continue with B.6 - Demographics]

c Don't remember

2 Where did your live at the time of the flood?

a City

b State

3 When did this flood event take place?

a Month

b Year 
4 Did you experience any damages caused by this flooding event?

a Yes

b No [continue with B.6 - Demographics]

c Don't remember [continue with B.6 - Demographics]

5 How much damage approximately and what percent of that total was covered by insurance?

a Total estimated cost of damages

b Percent of above total covered by insurance

Space for comments on your experience with flooding

\section{B.6. Demographics}

1 How do you learn about flood risk? (Select all that apply)

a I do not go out of my way to learn about flood risk

b Personal experience with flooding

c Experience of family/friends/colleagues

d Experience of neighbors

e FEMA flood maps

f News media

g Other sources, Please specify

2 [For each answer in Q1] Please indicate why:

a I trust this source of information

b My situation is similar to the source's situation

c I have no alternative information

$\mathrm{d}$ It is the best available information source

e Other reasons, Please specify

3 Approximately, what is your total annual household income?

a Less than $\$ 30,000$

b $\$ 30,000-\$ 49,999$

c $\$ 50,000-\$ 74,999$

d $\$ 75,000-\$ 99,999$

e $\$ 100,000-\$ 149,999$

f $\$ 150,000-\$ 199,999$

g $\$ 200,000$ or more

h Prefer not to answer

4 Would you like to receive an online summary of the results of this study?

a Yes

b No

5 For follow-up purposes only please provide the following information.

First name

Last name

Company

Email address

Phone number (or retype email address)

Room for final comments/suggestions/requests

Thank you for taking part in this important study.

\section{Appendix C. Seller survey}

Thank you for taking the time to help with our research on flood risk. The information you provide will be used to better understand market forces in housing. The questions should take about 10-15 min of your time.

The questions are divided into five sections:

- Introduction [Qualifying questions]

- Perceiving flood risk

- Protecting yourself from flood risk

- Selling your home

- Experience with flooding

- Demographics

\section{C.1. Introduction [Qualifiers]}

1 In what state do you live?

a [dropdown menu of states] 
2 Do you own your own home?

a Yes

b No [Disqualify and exit]

3 Are you currently selling your house or have you sold your house within the last twelve months?

a My house is currently on the market

b I've sold my house within the last twelve months

c Neither [Disqualify and exit]

4 [If "sold"] Where (in which state) was the house you recently sold?

a State: _______ [Disqualify and exit if not a flood risk state]

b Outside the US [Disqualify and exit]

5 [Screener] What was the interest rate for your mortgage when you sold your house?

a $7-8 \%$ [Disqualify and exit]

b 8-9\% [Disqualify and exit]

c $9-10 \%$ [Disqualify and exit]

d 10-11\% [Disqualify and exit]

e $>11 \%$ [Disqualify and exit]

f None of these [Proceed with survey]

\section{C.2. Perceptions of flood risk}

Definitions: The Federal Emergency Management Agency (FEMA) identifies flood hazards through statistical information such as data for river

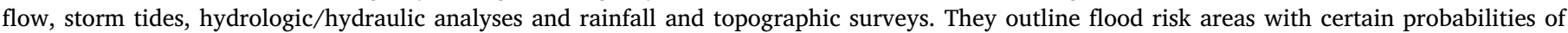
flooding, the 100-year flood zone and 500-year flood zone. They are defined as follows:

500-year flood zone: The area that has a $0.2 \%$ chance of being inundated by a flood event in any given year.

100-year flood zone: The area that has a 1\% chance of being inundated by a flood event in any given year.

1 [If selling] How likely is it that your house will get damage from flooding?

[If sold] How likely is it that the house that you have sold will get damage from flooding?

[4-point scale with only end labels: very likely, very unlikely]

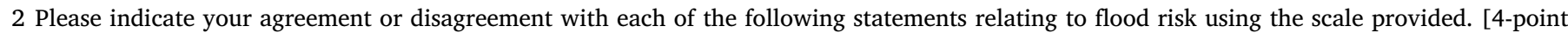
scale with only end labels: strongly agree, strongly disagree]

a If a property is in a 100-year flood zone, I would never buy this property

b If a property is in a 500-year flood zone, I would never buy this property

c If a property has been flooded before, I would not never buy this property

d I'm ok with living in a flood zone

e The risk of flooding deters me from buying property in the (100/500-year) flood zone.

$\mathrm{f}$ The cost of flood insurance deters me from buying property in the 100-year flood zone.

$\mathrm{g}$ I worry about the risk of flooding

$\mathrm{h}$ I fear the consequences of flooding

Space for comments on perceptions of flood risk

\section{C.3. Protecting yourself from flood risk}

1 [If selling] Which of the following did you do or are still planning to do for the home you are selling as ways to minimize your personal damage in case of flooding?

[If sold] Which of the following did you do for the home you sold as ways to minimize your personal damage in case of flooding? (Select all that apply)

a Installation of flood openings (vents), routes for water to drain

b Get flood insurance for your home

c Selling the house and move to a location outside the flood zone

d Elevating your home/Lifting the property or building the house on pilings

e Abandon lowest floor

f None of these

1 Please rate how effective you think each of the following measures is for reducing your risk?

[5-point scale with end labels: very effective/very ineffective + Not sure]

a Installation of flood openings (vents), routes for water to drain

b Get flood insurance for your home

c Selling the house and move to a location outside the flood zone 
d Elevating your home/Lifting the property or building the house on pilings

e Abandon lowest floor

2 Please rate how expensive you think each of the following measures is?

[5-point scale with end labels: very expensive/very inexpensive + Not sure]

a Installation of flood openings (vents), routes for water to drain

b Get flood insurance for your home

c Selling the house and move to a location outside the flood zone

$\mathrm{d}$ Elevating your home/Lifting the property or building the house on pilings

e Abandon lowest floor

3 [If selling] How easy or difficult do you consider these measures be for the home you are selling?

[If sold] How easy or difficult do you consider these measures be for the home you have sold?

[5-point scale with end labels: very easy/very difficult + Not sure]

a Installation of flood openings (vents), routes for water to drain

b Get flood insurance for your home

c Selling the house and move to a location outside the flood zone

d Elevating your home/Lifting the property or building the house on pilings

e Abandon lowest floor

\section{C.4. Selling your home}

The questions in this section relate to you selling your home. Several questions ask you to remember the process you went through when you sold your house or what you are going through as you sell your house.

1 [If selling] What is the main reason you are selling your house? (Select no more than three)

[If sold] What was the main reason you sold your house? (Select no more than three)

a Wanted a bigger, newer or nicer house

b To be closer to work/Job change

c Could not afford property anymore

d Retirement/downsizing

e Medical reasons

f Related to a divorce or separation

g Dissatisfaction with neighborhood

$\mathrm{h}$ Risk of natural hazards in that area

i Neighborhood deterioration

j Other (please specify)

2 What was your initial list price when you first put your property on the market?

a US dollars

3 [If selling] What is your current list price?

[If sold] For how much did you sell your house?

a Sales Price: US dollars

b Current List Price: US dollars

4 [If selling] What is the lowest price you would accept for your house?

[If sold] What was the lowest price you would have accepted for your house?

a US dollars

b Uncertain

5 [If selling] How long has your house been for sale?

[If sold] How long did it take to sell your house?

a Less than 3 months 
b 3-6 months

c 7-12 months

d 1-2 years

e 3 years or more

f Uncertain/Can't remember

6 [If selling] Approximately, how many showings of your house have you had?

[If sold] Approximately, how many showings of your house did you have?
a None
b $1-3$
c $4-10$
d $11-20$
e More than 20
f Uncertain

7 [If selling] Which of the following statements best represents your feelings about selling your house? (Select all that apply)

a My property is likely to sell quickly

b I will get a good price for my property.

c I am generally pessimistic about the chances of selling my property.

d I will likely end up taking less than my list price for my property.

e Uncertain

8 [If sold] Which of the following statements best represents your feelings about selling your house? (Select all that apply)

a My property sold quickly.

b I got a good price for my property.

c It took a long time to sell my property.

d I reduced my list price in order to sell my property.

e Uncertain

9 [If selling] Please provide the following information for your house:

[If sold] Please provide the following information for the house you sold:

a No. of bedrooms (please specify)

b Square footage (please specify*)

c No. of bathrooms (please specify)

d A garage $(\mathrm{Y}, \mathrm{N})$

e Built in year (please specify*)

f Acres of land (please specify*)

$\mathrm{g}$ Live on the water front $(\mathrm{Y}, \mathrm{N})$

$\mathrm{h}$ Live near the water $(\mathrm{Y}, \mathrm{N})$

i Outside the flood zone $(\mathrm{Y}, \mathrm{N})$

*a rough estimation is fine

10 [If selling] Where are you planning to move?

a The same city/area where I live now

b Another city/area in the same state

c In another state (please specify)

d Abroad (i.e. out of the country)

[If sold] Where did you move after selling your home?

a The same city/area where I used to live

b Another city/area in the same state

c In another state (please specify)

d Abroad (i.e. out of the country)

11 [If selling] Please provide the street address and city of your home.

[If sold] Please provide the street address and city of the house which you sold.

a Street address:

b City:

12 [If selling] Is your home in one of the flood zones? 
[If sold] Is the home you sold in one of the flood zones?

a Yes, it is in the 100-year flood zone

b Yes, it is in the 500-year flood zone

c Yes, but it's in a different flood zone, namely

d No, our house is outside of a flood zone [proceed to Q14]

e I don't know [proceed to Q14]

13 [If in flood zone] Approximately how much do you think your property would be worth if it was located outside the flood zone?

a Please specify amount US dollars

b Uncertain

14 [If selling] Does the house you are selling have any visible damage from flooding events?

[If sold] Did the house you sold have any visible damage from flooding events?

a Yes

b No [proceed to Q17]

c Don't know [proceed to Q17]

15 [If selling] Do these damages affect the value of the property in any way?

[If sold] Did these damages affect the value of the property in any way?

a Yes

b No [proceed to Q17]

c Don't know [proceed to Q17]

16 How much would your property be worth if your property wasn't damaged?

a Please specify amount ____ US dollars

17 [If selling] Is your neighborhood visibly affected by damage from flooding events?

[If sold] Is the neighborhood of the house you sold visibly affected by damage from flooding events?

a Yes

b No [proceed to Q20]

c Don't know [proceed to Q20]

18 [If selling] Do these damages affect the value of your property in any way?

[If sold] Did these damages affect the value of your property in any way?

a Yes

b No [proceed to Q20]

c Don't know [proceed to Q20]

19 How much would your property be worth if the neighborhood wasn't affected by floods?

a Please specify amount ___ US dollars

20 [If selling] Do you carry flood insurance on your home?

[If sold] Did you carry flood insurance on the home you sold?

a Yes

b No [proceed to IV - Experience with flooding]

c Uncertain [proceed to IV - Experience with flooding]

21 [If selling] What do you pay monthly for flood insurance?

[If sold] What did you pay monthly for flood insurance?

b $\overline{\text { Uncertain }}$
Space for comments on selling your home 


\section{C.5. Experience with flooding}

1 Did you ever personally experience a major flooding event in your town?

a Yes

b No [proceed to Q7]

c Don't remember [proceed to Q7]

2 Where did your live at the time of the flood?

a City

b State

3 When did this flood event take place?

a Month

b Year

4 Did your house sustain damage from the flood you mention above?

a Yes

b No [proceed to Q7]

5 What was the total damage to your house and property and what percent of that total was covered by insurance?

a Total damage: US dollars

b Percent covered by flood insurance:

6 [If selling] If you were to experience a flood in your home, what would you expect your personal damage to be and what percent of that total would be covered by insurance?

[If sold] If you had experienced a flood at the house you just sold, what would you have expected your personal damage to be and what percent of that total would have been covered by insurance?

a Total estimated cost of damages US dollars

b Percent of above total covered by insurance

Space for comments on your experience with flooding

\section{C.6. Demographics}

1 How do you learn about flood risk? (Select all that apply)

a I do not go out of my way to learn about flood risk

b Personal experience with flooding

c Experience of family/friends

d Experience of neighbors

e FEMA flood maps

f News media

g Other sources, Please specify

2 [For each answer in Q1] Please indicate why: (Select all that apply)

a I trust this source of information

b My situation is similar to the source's situation

c I have no alternative information

$\mathrm{d}$ It is the best available information source

e Other reasons, Please specify

3 Approximately, what is your total annual household income?

a Less than $\$ 30,000$

b $\$ 30,000-\$ 49,999$

c $\$ 50,000-\$ 74,999$

d \$75,000-\$99,999

e $\$ 100,000-\$ 149,999$

f $\$ 150,000-\$ 199,999$

g $\$ 200,000$ or more

h Prefer not to answer

4 Would you like to receive an online summary of the results of this study?

a Yes

b No

5 For follow-up purposes only please provide the following information.

First name

Last name

Company

Email address

Phone number (or retype email address) 
Room for final comments/suggestions/requests

Thank you for taking part in this important study.

\section{Supplementary materials}

Supplementary material associated with this article can be found, in the online version, at doi:10.1016/j.gloenvcha.2019.101981.

\section{References}

Adger, W.N., Arnell, N.W., Tompkins, E.L., 2005. Successful adaptation to climate change across scales. Glob. Environ. Change 15 (2), 77-86.

Alexander, K.S., Ryan, A., Measham, T.G., 2012. Managed retreat of coastal communities: understanding responses to projected sea level rise. J. Environ. Plan. Manag. 55 (4), 409-433.

Atreya, A., Ferreira, S., Kriesel, W., 2012. Forgetting the flood? Changes in flood risk perceptions over time. In: Flood risk and homeowners' flood risk perceptions: evidence from property prices in Georgia, pp. 5-36.

Beltrán, A., Maddison, D., Elliott, R.J., 2018. Is flood risk capitalised into property values? Ecol. Econ. 146, 668-685.

Bin, O., Kruse, J.B., 2006. Real estate market response to coastal flood hazards. Nat. Hazards Rev. 7 (4), 137-144.

Bin, O., Kruse, J.B., Landry, C.E., 2008. Flood hazards, insurance rates, and amenities: evidence from the coastal housing market. J. Risk Insurance 75 (1), 63-82.

Bin, O., Landry, C.E., 2013. Changes in implicit flood risk premiums: empirical evidence from the housing market. J. Environ. Econ. Manag. 65 (3), 361-376.

Black, R., Arnell, N.W., Adger, W.N., Thomas, D., Geddes, A., 2013. Migration, immobility and displacement outcomes following extreme events. Environ. Sci. Policy 27, S32-S43.

Black, R., Kniveton, D., Schmidt-Verkerk, K., 2011. Migration and climate change: towards an integrated assessment of sensitivity. Environ. Plan. A 43 (2), 431-450.

Botzen, W.J.W., Aerts, J.C.J.H., Van Den Bergh, J.C.J.M., 2009. Dependence of flood risk perceptions on socioeconomic and objective risk factors. Water Resour. Res. 45 (10).

Bubeck, P., Botzen, W.J., Aerts, J.C., 2012. A review of risk perceptions and other factors that influence flood mitigation behavior. Risk Anal. 32 (9), 1481-1495.

Bubeck, P., Botzen, W.J., Kreibich, H., Aerts, J.C., 2013. Detailed insights into the influence of flood-coping appraisals on mitigation behaviour. Glob. Environ. Change 23 (5), 1327-1338.

Daniel, V.E., Florax, R.J., Rietveld, P., 2009. Flooding risk and housing values: an economic assessment of environmental hazard. Ecol. Econ. 69 (2), 355-365.

De Koning, K., Filatova, T., Bin, O., 2018. Improved methods for predicting property prices in hazard prone dynamic markets. Environ. Resour. Econ. 69 (2), 247-263.

Dronkers, J., Gilbert, J.T.E., Butler, L.W., Carey, J.J., Campbell, J., James, E., McKenzie, C., Misdorp, R., Quin, N., Ries, K.L., Schroder, P.C., Spradley, J.R., Titus, J.G., Vallianos, L., von Dadelszen, J., 1990. Strategies for Adaptation to Sea Level Rise. Report of the IPCC Coastal Zone Management Subgroup: Intergovernmental Panel on Climate Change. Intergovernmental Panel on Climate Change, Geneva.

van Duinen, R., Filatova, T., Geurts, P., Veen, A.V.D., 2015. Empirical analysis of farmers' drought risk perception: objective factors, personal circumstances, and social influence. Risk Anal. 35 (4), 741-755.

Ellison, A.M., 2004. Bayesian inference in ecology. Ecol. Lett. 7 (6), 509-520.

FEMA, 2015. FEMA P-1037, Reducing Flood Risk to Residential Buildings That Cannot be Elevated. https://www.fema.gov/media-library/assets/documents/109669.

Filatova, T., 2014. Market-based instruments for flood risk management: a review of theory, practice and perspectives for climate adaptation policy. Environ. Sci. Policy $37,227-242$.

Freudenberg, R., Calvin, E., Tolkoff, L., Brawley, D., 2016. Buy-In for buyouts: the case for managed retreat from flood zones. Lincoln Inst. Land Policy.

Ge, Y., Peacock, W.G., Lindell, M.K., 2011. Florida households' expected responses to hurricane hazard mitigation incentives. Risk Anal. 31 (10), 1676-1691.

Grothmann, T., Reusswig, F., 2006. People at risk of flooding: why some residents take precautionary action while others do not. Nat. Hazards 38 (1-2), 101-120.

Hallstrom, D.G., Smith, V.K., 2005. Market responses to hurricanes. J. Environ. Econ. Manag. 50 (3), 541-561.

Ho, M.C., Shaw, D., Lin, S., Chiu, Y.C., 2008. How do disaster characteristics influence risk perception? Risk Anal. 28 (3), 635-643.

Howson, C., Urbach, P., 2006. Scientific Reasoning: The Bayesian Approach. Open Court Publishing.

IPCC, 2012. Managing the Risks of Extreme Events and Disasters to Advance Climate Change Adaptation. In: Field, C.B. (Ed.), Managing the Risks of Extreme Events and Disasters to Advance Climate Change Adaptation. Cambridge Univ. Press, Cambridge.

Jongman, B., Ward, P.J., Aerts, J.C.J.H., 2012. Global exposure to river and coastal flooding: long term trends and changes. Glob. Environ. Change 22, 823-835.

Kahneman, D., Tversky, A., 1979. Prospect theory: an analysis of decisions under risk. Econometrica 47 (2), 263-292.

Katapodi, M.C., Lee, K.A., Facione, N.C., Dodd, M.J., 2004. Predictors of perceived breast cancer risk and the relation between perceived risk and breast cancer screening: a meta-analytic review. Prev. Med. 38 (4), 388-402.
Kates, R.W., Travis, W.R., Wilbanks, T.J., 2012. Transformational adaptation when incremental adaptations to climate change are insufficient. Proc. Natl. Acad. Sci. 109, 201115521.

Kellens, W., Terpstra, T., De Maeyer, P., 2013. Perception and communication of flood risks: a systematic review of empirical research. Risk Anal. 33 (1), 24-49.

Keller, C., Siegrist, M., Gutscher, H., 2006. The role of the affect and availability heuristics in risk communication. Risk Anal. 26 (3), 631-639.

Koerth, J., Vafeidis, A.T., Hinkel, J., 2017. Household-level coastal adaptation and its drivers: a systematic case study review. Risk Anal. 37 (4), 629-646.

Kousky, C., 2010. Learning from extreme events: risk perceptions after the flood. Land Econ. 86 (3), 395-422.

Lindell, M.K., Hwang, S.N., 2008. , households' perceived personal risk and responses in a multihazard environment. Risk Anal. 28 (2), 539-556.

National Hurricane Centre, 2018. Costliest U.S. Tropical Cyclones Tables Updated. https://www.nhc.noaa.gov/news/UpdatedCostliest.pdf.

National Weather Service, 2018. Hydrologic Information Center - Flood Loss Data. http://www.nws.noaa.gov/hic.- visited 20/9/2018.

Osberghaus, D., 2017. The effect of flood experience on household mitigation-evidence from longitudinal and insurance data. Glob. Environ. Change 43, 126-136.

Poussin, J.K., Botzen, W.W., Aerts, J.C., 2014. Factors of influence on flood damage mitigation behaviour by households. Environ. Sci. Policy 40, 69-77.

Pryce, G., Chen, Y., Galster, G., 2011. The impact of floods on house prices: an imperfect information approach with myopia and amnesia. Hous. Stud. 26 (02), 259-279.

Rey-Valette, H., Robert, S., Rulleau, B., 2019. Resistance to relocation in flood-vulnerable coastal areas: a proposed composite index. Clim. Policy 19 (2), 206-218.

Rosen, S., 1974. Hedonic prices and implicit markets: product differentiation in pure competition. J. Pol. Econ. 82 (1), 34-55.

Slovic, P., Finucane, M.L., Peters, E., MacGregor, D.G., 2004. Risk as analysis and risk as feelings: some thoughts about affect, reason, risk, and rationality. Risk Anal. 24 (2), 311-322.

Slovic, P., Peters, E., Finucane, M.L., MacGregor, D.G., 2005. Affect, risk, and decision making. Health Psychol. 24 (4S), S35.

Song, J., Fu, X., Wang, R., Peng, Z.R., Gu, Z., 2018. Does planned retreat matter? Investigating land use change under the impacts of flooding induced by sea level rise. Mitig. Adapt. Strateg. Glob. Change 23 (5), 703-733.

Terpstra, T., 2011. Emotions, trust, and perceived risk: affective and cognitive routes to flood preparedness behavior. Risk Anal. 31 (10), 1658-1675.

Treuer, G., Broad, K., Meyer, R., 2018. Using simulations to forecast homeowner response to sea level rise in South Florida: will they stay or will they go? Glob. Environ. Change 48, 108-118.

Trumbo, C., Meyer, M.A., Marlatt, H., Peek, L., Morrissey, B., 2014. An assessment of change in risk perception and optimistic bias for hurricanes among Gulf Coast residents. Risk Anal. 34 (6), 1013-1024.

UNISDR, 2011. Global Assessment Report on Disaster Risk Reduction. GAR11.

Van Valkengoed, A.M., Steg, L., 2019. Meta-analyses of factors motivating climate change adaptation behaviour. Nat. Clim. Change 1, 158-163.

Weinstein, N.D., 2000. Perceived probability, perceived severity, and health-protective behavior. Health Psychol. 19 (1), 65.

Weinstein, N.D., Kwitel, A., McCaul, K.D., Magnan, R.E., Gerrard, M., Gibbons, F.X. 2007. Risk perceptions: assessment and relationship to influenza vaccination. Health Psychol. 26 (2), 146.

Winsemius, H.C., Aerts, J.C.J.H., van Beek, L.P.H., Bierkens, M.F.P., Bouwman, A., Jongman, B., Kwadijk, J.C.J., Ligtvoet, W., Lucas, P.L., van Vuuren, D.P., Ward, P.J., 2016. Global drivers of future river flood risk. Nat. Clim. Change 6, 381-385.

Wong, P.P., Losada, I.J., Gattuso, J.-.P., Hinkel, J., Khattabi, A., McInnes, K.L., Saito, Y., Sallenger, A., 2014. Coastal systems and low-lying areas. In: Field, C.B., Barros, V.R., Dokken, D.J., Mach, K.J., Mastrandrea, M.D., Bilir, T.E., Chatterjee, M., Ebi, K.L., Estrada, Y.O., Genova, R.C., Girma, B., Kissel, E.S., Levy, A.N., MacCracken, S., Mastrandrea, P.R., White, L.L. (Eds.), Climate Change 2014: Impacts, Adaptation, and Vulnerability. Part A: Global and Sectoral Aspects. Contribution of Working Group II to the Fifth Assessment Report of the Intergovernmental Panel On Climate Change. Cambridge University Press, Cambridge, United Kingdom and New York, NY, USA, pp. 361-409.

Zaalberg, R., Midden, C., Meijnders, A., McCalley, T., 2009. Prevention, adaptation, and threat denial: flooding experiences in the Netherlands. Risk Anal. 29 (12), 1759-1778.

Zaninetti, J.M., Colten, C.E., 2012. Shrinking New Orleans: post-Katrina population adjustments. Urban Geogr. 33 (5), 675-699.

Zillow, 2018. Data, Home Values. https://www.zillow.com/research/data/- downloaded $13 / 3 / 2018$ 